Article

\title{
Because My Friends Insist or Because It Makes Sense? Adolescents' Motivation towards the Environment
}

\author{
Jelle Boeve-de Pauw * and Peter Van Petegem \\ Research unit Edbron, Department of Training and Education Sciences, University of Antwerp, Prinsstraat 13, \\ 2000 Antwerp, Belgium; peter.vanpetegem@uantwerp.be \\ * Correspondence: jelle.boevedepauw@uantwerp.be; Tel.: +32-265-55-54
}

Academic Editor: Ingo Eilks

Received: 27 February 2017; Accepted: 2 May 2017; Published: 4 May 2017

\begin{abstract}
We present the results of a study that focuses in on issues of validity of the motivation towards the environment scale (MTES) in the context of Flanders (the Flemish-speaking community in Belgium). The instrument was developed almost two decades ago in Canada, and is designed to measure the self-determined motivation of people for performing pro-environmental behaviors, but has not yet been applied widely to different contexts. Here, we use a sample of 1730 grade 12 students from 71 schools across Flanders, to focus on specific issues concerning the validity of the MTES in the context of Flanders. We deal with its construct validity, through the estimation of a confirmatory factor analysis. Next, we test the reliability of the MTES and the hypothesized simplex structure by calculating intercorrelations between all six MTES subscales. External validity of the MTES is addressed by correlating the subscales to well-established environmental psychological constructs, such as the models of two major environmental values, the connectedness to nature scale, and the general ecological behavior scale. Finally, we also look at the discriminative validity of the MTES by testing gender differences in self-determined motivations towards the environment. Overall, our results confirm that the MTES is a valid and reliable instrument that can also be used outside the cultural context within which it was developed, to measure the diverse motivations of (young) people to engage in environmental behavior.
\end{abstract}

Keywords: MTES; motivation; self-determination; adolescents

\section{Introduction}

Only rarely do we hear positive news about the state of the natural environment. Human actions have resulted in acid rain, shrinking rainforests, and expanding deserts. Species are disappearing at unprecedented rates [1], the oceans contain vast islands of floating debris [2], and the air we breathe is soiled by particulate emissions [3]. The list of human-induced environmental problems is ever-growing. Most of these problems are not as a result of malicious intent but rather as a consequence of the lifestyle of billions of people [4]. Moreover, these problems are not only detrimental to the natural environment, they also threaten human well-being [5]. Balmford and Crowling note that "conservation is primarily not about biology but about people and the choices they make" [6]. Schultz et al. go one step further and posits that conservation is a goal that can only be achieved by changing behavior [7].

Social scientists and psychologists have extensively studied the environmental behavior of individuals, and several theoretical models exist that explain the causation of and variation in such behavior between individuals and groups of people. In an effort to understand and change behavior, several psychosocial variables (that are hypothesized to be formed through education, outreach or sensitization) have been the focus of scholarly attention. Knowledge is seen by some as an important precondition for environmental behavior, in the premise that knowing more about the environment ("system knowledge") or about the consequences of your own behavior ("impact knowledge") could 
promote, or at least facilitate, pro-environmental behavior [8]. Furthermore, much attention has been devoted to the importance of attitudes, values or worldviews, with a resulting battery of psychometric instruments to tap into these constructs. The most well-known and widely-used are the new ecological paradigm (NEP) [9] and the two major environmental values [10] model (2MEV). Increasingly, there is also interest in more affective constructs and their relation to environmental behavior, examples of which are the inclusion of nature in the self scale (INS) [11] and the connectedness to nature scale (CNS) [12].

Many more constructs and instruments exist; some scholars have even claimed that the number of instruments approaches the number of researchers active in this field. Many of the instruments fit within a tradition of explaining environmental behaviors through models, such as the theory of planned behavior [13], of the value-belief-norm model [14]. These theories and constructs have also found their way into evaluation practices and studies of (for example) environmental education. Such studies typically not only look at environmental behaviors as measures of success for educational initiatives, but also include psychosocial precedents such as knowledge, attitudes, connectedness, etc. [15-17]. Another approach to look at the causation of behavior is that of motivation. Rather than investigating what causes specific behaviors, this approach looks at the "why" of such behaviors: what kinds of motives lay at their root? Are they performed because one feels obligated to perform them, are they consequences of people avoiding being criticized by others (or maybe even fined), or is there some intrinsic value to performing a specific behavior? A particularly interesting view at behaviors through the lens of motivation is offered by Self-Determination Theory (SDT) [18].

SDT has, for more than 40 years, allowed for the empirical examination of forms of motivation and the conditions that support them. The theory originated from the idea of intrinsic motivation for performing certain behaviors; actions motivated purely by the rewarding qualities of the experience they provide [19]. Osbaldistan and Sheldon [20], however, describe how many important behaviors cannot be intrinsically motivated, and that this observation is at the root of the expansion of the SDT into a "comprehensive theoretical account of the social and intrapersonal processes by which important duties are internalized [21] such that individuals perform behaviors willingly even when they do not enjoy those behaviors" (p. 349). When we think about ecologically responsible behavior such as sorting waste into the correct bins, switching off of lights when leaving the room or taking shorter showers, it is clear that they are likely to fall into this category.

SDT does not just zoom in on intrinsic motivation, it distinguishes among three kinds of motivations for a behavior: intrinsic, extrinsic, and amotivation. These motivations spread out across a continuum reflecting the extent to which they are autonomously rooted in the individual. As described above, intrinsically motivated behaviors are the most autonomous: individuals engage in them for the intrinsic pleasure of performing them. Extrinsic motivation refers to a variety of instrumental behaviors; they are performed as a means to an end [22]. Deci and Ryan [21] define four kinds of external motivation: external regulation, introjection, identification, and integration. External regulation refers to behaviors motivated by external sources; for example, a student that recycles her waste only because the teacher makes her do it. Such motivations reflect the lowest form of autonomy, since the reason for their adoption comes from outside the person. When it comes to introjected regulation, the control over the behavior is more internalized, and the drivers for the behavior relate to emotions such as self-esteem and even punishment from internal sources such as guilt and shame. Pelletier, Tuson, Green-Demers, Noels, and Beaton [23] describe that behaviors can gain enough importance in the individual's mind to be valued in themselves, and become regulated by identification. The behavior is still instrumental, but external motives have been sufficiently internalized to cause an individual to identify with the behavior in question. Integrated regulation, then, occurs when an instrumental behavior has been valorized to such an extent that it becomes part of a person's core sense of self. Amotivation, on the other extreme end, reflects a sense of non-ability to control the goals intended to be affected by the behavior, or that the outcomes of the behavior do not make a difference. A typical example is the persuasion that your own actions can never have such 
an impact that they contribute to the mitigation of vast and complex issues such as climate change. Amotivation creates feelings of incompetence and lack of control.

The different forms of motivation are typically assessed by asking respondents about the reasons for performing various behaviors. In 1998, Pelletier and his team developed a scale through which the SDT can be used to understand environmental behavior. Their results show that self-motivated behaviors predict more frequent enactment of such behaviors and also predict environmental satisfaction, environmental responsibility, and self-efficacy for environmental behavior. In a later study, the same team [24] used their motivation towards the environment scale (MTES) to study the impact of an educational initiative: the Brundlandt schools. The results showed that adolescents and parents in experimental and control schools did not differ in terms of their motivation towards the environment, indicating a failure of the program to reach its goals. In their studies, the different subscales showed good psychometric properties. The instrument thus provides a potentially valuable method to study the environmental behavior of adolescents through the SDT, and in that constitutes an interesting alternative measure that can be used as outcome criteria for (educational) interventions dealing with environmental issues. Such interventions rarely try to overtly change participants' environmental behaviors, but rather they aim to impact what underlies such behaviors. Therefore, the goal is often to move participants away from amotivation and towards more autonomous forms of motivation.

Table 1. Items and scales of the MTES.

\begin{tabular}{|c|c|}
\hline IM & Intrinsic Motivation \\
\hline IM1 & Pleasure in mastering new ways to help \\
\hline IM2 & Pleasure in improving the quality of the environment \\
\hline IM3 & Pleasure when doing things for the environment \\
\hline IM4 & Pleasure in contributing to the environment \\
\hline INTEG & Integrated Regulation \\
\hline INTEG1 & An integral part of my life \\
\hline INTEG2 & Seems that taking care of myself and environment are inseparable \\
\hline INTEG3 & Has become a fundamental part of who I am \\
\hline INTEG4 & Part of the way I've chosen to live \\
\hline IDEN & Identified Regulation \\
\hline IDEN1 & Is a sensible thing to do \\
\hline IDEN2 & A way I have chosen to contribute \\
\hline IDEN3 & Is a reasonable thing to do \\
\hline IDEN4 & A good idea to do something about the environment \\
\hline INTRO & Introjected Regulation \\
\hline INTRO1 & I'd regret not doing something \\
\hline INTRO2 & Would feel guilty if I didn't \\
\hline INTRO3 & Would feel bad if I didn't do anything \\
\hline INTRO4 & Would feel ashamed if I didn't \\
\hline ER & Externally Regulated \\
\hline ER1 & Other people will be upset if I don't \\
\hline ER2 & For the recognition I get from others \\
\hline ER3 & Because my friends insist that I do \\
\hline ER4 & To avoid being criticized \\
\hline AMO & Amotivation \\
\hline AMO1 & I wonder why; the situation isn't improving \\
\hline $\mathrm{AMO} 2$ & Don't know, have the impression I am wasting time \\
\hline $\mathrm{AMO} 3$ & Don't know, can't see how my efforts are helping \\
\hline $\mathrm{AMO} 4$ & Don't know, can't see what I'm getting out of it \\
\hline
\end{tabular}

$\mathrm{IM}=$ intrinsic motivation; INTEG = integrated regulation; IDEN = identified regulation; INTRO = introjected regulation; $\mathrm{ER}=$ external regulation; $\mathrm{AMO}=$ amotivation.

The Pelletier team originally designed the MTES to contain 60 items [23], 10 for each of the different motivational constructs. Through a combination of exploratory and confirmatory factor 
analytical techniques, they reduced the number of items to 24 (four for each of the constructs). Table 1 shows the 24 items of the MTES developed in 1998 [23]. Villacorta et al. [25] further validated this shortened version of the scale, with a focus on its convergent and discriminant validity, by showing that peer-reports correspond to self-reports of environmental self-regulation and that environmental-self regulation was relatively distinct from self-regulation in academic and political domains. With the current paper, we want to examine the validity and reliability of the MTES in a different cultural context (Flanders, the Flemish-speaking community of Belgium) than the one where it was developed (Canada).

Beside investigating the construct validity and reliability of the MTES in Flanders, a major focus of the current study is on the external validity of the MTES. In line with the approach of De Groot and Steg [26], who related motivational types to value orientations [27] and pro-environmental intentions [28,29], we will relate the MTES subscales to several well-established constructs from contemporary environmental psychology. The first such construct is the two major environmental values (2-MEV) model [10]. This construct sees environmental values divided into two independent dimensions. The first, preservation, entails a set of attitudes that center around preserving the natural environment. The second, utilization, focuses on the use of natural resources for the benefit of humankind. The two are not theorized as extremes of a single dimension, but rather two independent orthogonal dimensions: scoring high on one of them does therefore not imply a low score on the other. The instrument therefore allows for individual respondents to show an integrated set of values that favor both preservation and utilization. Milfont, Duckitt, and Cameron [30] describe that, for this reason, the instrument is very suited to the measurement of values within the contemporary framework of the psychology of sustainable development. Our hypothesis is that the more self-determined forms of motivation towards the environment correlate positively to the preservation dimension, while the more controlled regulation styles correlate to the utilization dimension. Since preservation and utilization are not opponents to each other [31], we do not hypothesize a negative correlation between utilization and self-determined motivation, nor between preservation and the more controlled regulation styles; however, we do hypothesize value-specific correlations to the MTES dimensions.

Another construct we use to study the external validity of the MTES is the connectedness to nature scale (CNS) [12]. Frantz and Mayer [32] argue that the deep motivation that comes from a sense of "we-ness" is one of the few psychological forces strong enough to compete with the prevailing counterforces required to engage in environmentally responsible behavior. Finally, we also correlate the different MTES dimensions to the self-reported environmental behavior. To this end, we use Kaiser, Oerke and Bogner's [33] general ecological behavior (GEB) scale. This scale was designed specifically to tap into the ecological behavior of adolescents. Its sees six big domains in which such behaviors can be categorized: energy conservation, mobility and transportation, waste avoidance, consumerism, recycling, and vicarious behaviors towards conservation. We hypothesize that self-reported behaviors correlate more strongly to the more self-determined dimensions of the MTES, with the correlations shrinking as we move toward the controlled dimensions. Between amotivation and self-reported behavior it is reasonable to presume a negative correlation. Furthermore, it can be expected that the different behaviors correlate differently to the different forms of motivation, with the "easier" behaviors to agree with and perform corresponding differently to the MTES dimensions than the "more difficult" behaviors. Furthermore, the specific context of adolescents, who spend a great deal of their time experiencing external control over their own behaviors either inside school walls or within their family, needs to be taken into account. Recycling is, for example, a typical ecological behavior that - in Flemish schools—is heavily subjected to school rules and regulations, and thus might also occur in accordance with external regulation.

A major issue in research on environmentalism is that of gender differences [34]. In our current study, we will zoom in on gender differences in motivation toward the environment. Such differences can be hypothesized to exist both from the body of literature on environmentalism and from that on self-determination. Gender differences in environmentalism have been illustrated for adults [35], young adults [36], and children [34]; for each of these age groups, woman (and girls) have been shown 
to be more environmentalist than men (and boys). A widely-used approach to explain these gender differences is based on gender roles and socialization [34]. Socialization theory posits that individuals are shaped by gender expectations within the context of cultural norms. Females across cultures are socialized to be more expressive, to have a stronger ethic of care, and to be more interdependent, compassionate, nurturing, cooperative, and helpful in caregiving roles; males, however, are socialized to be more independent and competitive [37]. These differences in socialization between the genders could then be reflected in their environmentalism [34]. Studies focusing on motivation in domains other than the environmental one, illustrate that gender differences can be expected in accordance with a degree of self-determination of the motivation. Vallerand et al. [38] showed that women report higher levels of intrinsic academic motivation and that men show higher levels of externally regulated academic motivation and amotivation. Gender also has effects on children's intrinsic motivation for reading, writing, and math [39]. Specifically, girls have higher intrinsic motivation for writing and reading as well as higher identified regulation for writing than boys. In contrast, boys have higher intrinsic motivation for math than girls. We hypothesize a confirmation of gender differences in the MTES, and consider them as such an indication of the discriminatory validity of the MTES.

\section{Aim of the Study}

The current study addresses different issues of validity and reliability of the MTES in the context of Flemish adolescents. The study is built around four major analytical steps. In the first, we aim to confirm the factor structure of the MTES through Confirmatory Factor Analysis (CFA). Pelletier et al. (1998) developed the scale to contain six subscales: one for each form of the five forms of motivation (intrinsic, integrated, identified, introjected, external regulation), and one for amotivation. The third step zooms in the external validity of the MTES by estimating correlations between the different forms of motivation and several other well-established constructs in conservation psychology: the 2-MEV (including preservation and utilization values [10]), the connectedness to nature scale (CNS) [12], and general ecological behavior (GEB) [33]. In the fourth and final step, we focus on gender differences in the motivation towards the environment of Flemish adolescents. The overall focus of the study is to tackle key validity issues regarding the Flemish version on the MTES. The research aims can as such be summarized into:

1. Can we establish the construct validity of the Flemish version of the MTES?

2. Can we replicate the simplex pattern of self-determination for the Flemish MTES?

3. Does the Flemish version of the MTES hold external validity (2MEV, CNS, and GEB)?

4. Can the Flemish version of the MTES detect gender differences?

\section{Methodology}

Sample. The study is based on a sample of 1730 respondents from 71 schools. All respondents are in the last year of secondary education (grade 12) and are aged 17-18 years. The sample was collected in the spring of 2013 as part of a large scale study that focused on the environmental literacy of adolescents, and has a balanced gender ratio (girls:boys 0.92). Data was collected in Flanders (the Flemish-speaking community in Belgium). Data was collected online during school hours. School coordinators gathered students in the computer lab of their school, distributed logins to the online survey and supervised the students while responding. School coordinators were instructed not to have any other interactions with the students besides providing technical assistance when needed. Data was collected anonymously, and passive consent was included in the online data collection tool.

Measures-Motivation towards the Environment. We created a Flemish translation of the MTES, which we used to measure the self-determined motivation toward the environment of Flemish adolescents. The Flemish language version of each item was created using a back translation protocol. First, all items were translated by one author from English into Flemish. In a second step, an independent researcher translated the Flemish items back to English, and both English versions of 
the items were checked for consistency in their meaning and interpretation. No problematic translation issues were reported.

Measures-Environmental Values. To tap into the environmental values of our respondents, we used the 2006 version of Bogner and Wiseman's 2-MEV [10]. While earlier versions of the scale distinguish between five attitudes grouped into two values, the more recent version only taps into the two second order factors (the values). Previous studies have shown this higher order version to be highly reliable, with reported Cronbach's alphas ranging between 0.71 and 0.94 for preservation and between 0.68 and 0.79 for utilization. Boeve-de Pauw, Jacobs and Van Petegem [31] confirmed the scales factor structure in a Flemish sample. A sample item for the preservation dimension is "we need to set aside pieces of nature to protect endangered species", a sample item for utilization is "we should remove weeds from our gardens so that beautiful flowers can grow". As designed, the respondents answered to the question 'how much do you agree with this statement?' for each of the twenty 2-MEV items on a five-point Likert scale with answering categories corresponding to "strongly disagree, disagree, neither agree nor disagree, agree, strongly agree". Each of the two dimensions entails 10 items, and our analyses show good reliability with an alpha of 0.87 for preservation and 0.71 for utilization.

Measures-Connectedness to Nature. The CNS is a similar Likert-type scale and encompasses seventeen items to which the adolescents in our sample responded to one of the five answer categories ("totally disagree, disagree, neither agree nor disagree, agree, totally agree"). Sample items for the CNS are "I feel that I belong as strong to the earth as the earth belongs to me" and "I often feel a sense of unity with the nature that surrounds me". The seventeen CNS items together tap into a single dimension of connectedness. We report an excellent alpha of 0.92 for the CNS. Other scholars have reported similar results for the reliability of the CNS [32].

Measures-General Ecological Behavior. GEB data is only available for a subset of our sample and, due to pragmatic issues (mainly place restriction in the survey), not all six GEB dimensions could be included. We did include recycling, mobility, energy-saving, and vicarious behaviors. Each of the dimensions was tapped through four items, in which the respondents had to indicate how often they performed such a behavior on a five-point Likert scale: "never, very seldom, seldom, often, all the time". A sample item for recycling is "for making notes, I take paper that is already used on one side", for mobility "I ride a bicycle, take publication transport or walk to school rather than go by car", for energy "I leave electric appliances (TV, stereo, smartphone) on stand-by mode when I do not use them", and for vicarious behaviors "I ask my parents to buy seasonal produce". The alphas for the behavioral dimensions range between 0.71 and 0.84 , which is in line with results from other studies [33]. The correlations were calculated between latent constructs. Based on the arguments of Perenger [40] and O'Keefe [41], we did not adjust the alpha level to the number of tests.

Analyses. For the first and second steps (factor structure of the MTES and reliability estimates), we used all MTES data $(n=1730)$ in one single CFA to empirically confirm the construct validity of the MTES. Analyses were performed using the statistical software package Mplus [42]. To evaluate the model fit, multiple fit indices were used with minimum values around 0.95 for the Comparative Fit Index (CFI) and the Tucker-Lewis Index (TLI), and a value of 0.06 or less for the Root Means Square Error of Approximation (RMSEA) [43]. Since all data was ordered categorical by nature, the weighted least squares means and variance (WLSMV) estimator was used with delta parameterization [44]. The CFA was not estimated in a multilevel approach, but we did include corrections of estimates for the hierarchical dependency of the data (students clustered within schools) through the Mplus type $=$ complex command .

We used the entire sample $(n=1730)$ to calculate the internal consistency of the six subscales (Cronbach's alpha). We also provide descriptive statistics. All items were Likert-type scale possible answers to the same question: why are you doing things for the environment? The respondents were asked to indicate the extent to which each of the possible answers corresponds to their own motives for performing environmental behaviors. The answers were given on a seven-point scale, ranging from $1=$ "does not correspond at all", over $4=$ "corresponds moderately", to $7=$ "corresponds 
exactly". There was no "I don't know" answering point included in the possibilities. In the survey, the items were not grouped per subscale, but rather they were randomly scrambled. For this study, we present the reliability and mean scores plus standard deviations for the MTES, and also the correlations between the different subscales.

The correlations are calculated both using the raw data (Pearsons) and between the latent factors in the CFA. Gender differences (step 4) were studied using independent sample $t$-tests. Statistical significance was accepted at $p<0.05$, and practical significance was judged using Cohen's $d$. When multiple (correlation) tests are run on the same data, it is common practice to adjust the alpha level $(p<0.05)$ to the number of tests run, in order to not inflate the chance of obtaining statistically significant results. Such practices have, however, been shown to have no principled basis [40] and to be deleterious to sound statistical inference [41], which is why we did not adjust the $\alpha$-level to the number of tests.

\section{Results}

MTES Construct Validity. The six-factor model as presented by Pelletier et al. [23] showed excellent fit indices, with RMSEA $=0.05(p=0.000,0.05<$ RMSEA $<0.04)$, CFI $=0.95$, TLI $=0.94)$. No modifications of indices were observed, which would suggest problematic covariances between items belonging to different subscales. Moreover, all items loaded significantly onto their subscale, and the pattern of factor loadings within each subscale were harmonious, with all items showing loadings of similar importance of the reference item fixed at 1.000. Figure 1 shows the six-factor model of the MTES; the model includes error variances for all 24 items, factor variances for all six factors, and correlations between all factors.
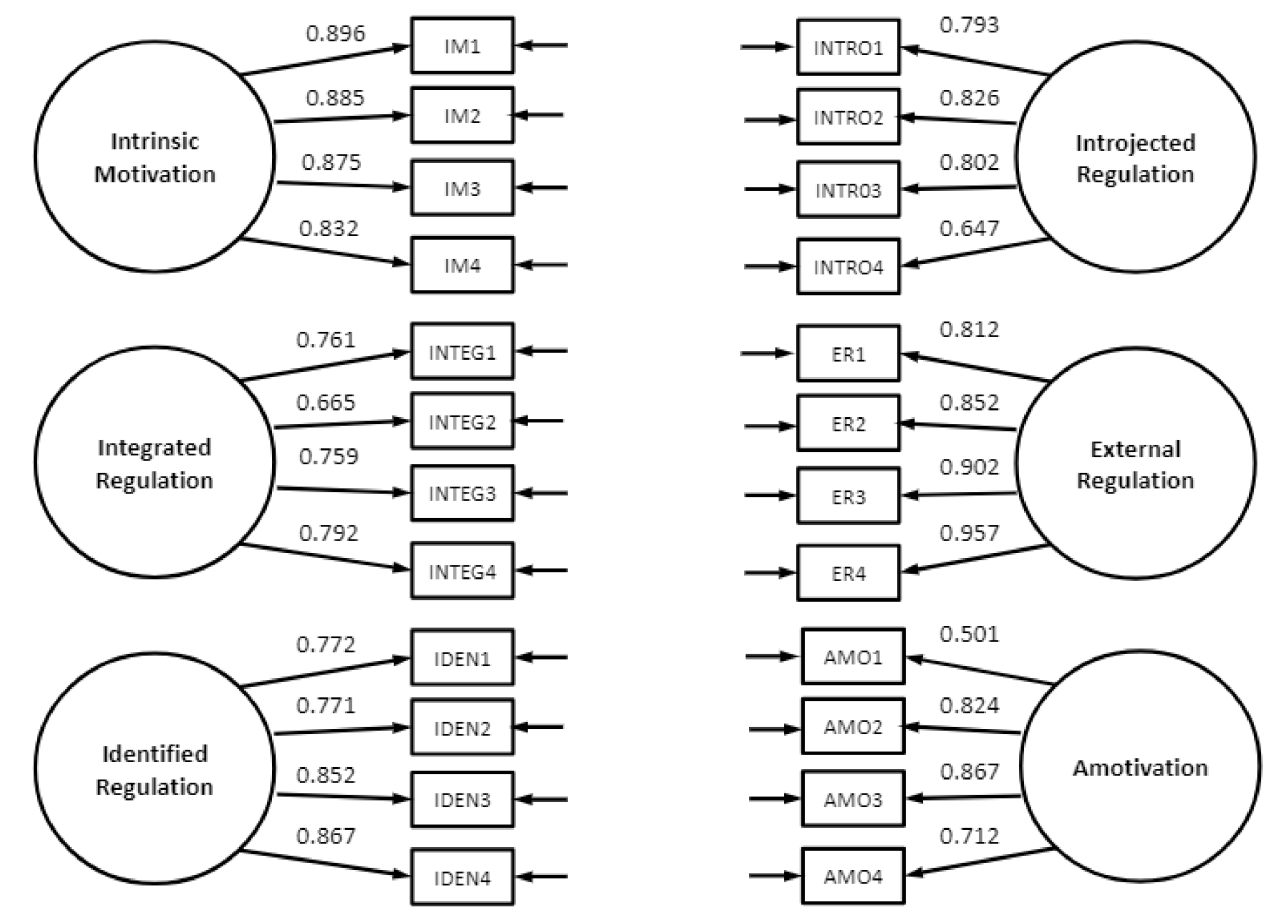

Figure 1. Confirmatory factor analysis for the motivation towards the environment scale (MTES), factor loadings are standardized.

MTES Reliability, Descriptives, and Simplex Structure. All subscales showed good to high reliability, with all alphas around 0.90. This corresponds very well to earlier studies that have used the MTES; for the six subscales, Pelletier et al. [23] and Villacorta et al. [25] respectively report alphas for intrinsic motivation (IM) 0.89 and 0.89 , for integrated regulation 0.92 and 0.88 , for identified regulation 0.89 and 
0.81 , for introjected regulation 0.71 and 0.83 , for external regulation 0.81 and 0.83 , and for amotivation 0.83 and 0.75 . Reliability estimates as well as descriptives for all MTES subscales and items are provided in Table 2.

Table 2. Scale reliabilities and item descriptive statistics for MTES.

\begin{tabular}{|c|c|c|c|c|}
\hline & Scale/Item & & $\mathbf{M}$ & SD \\
\hline IM & Intrinsic motivation & $\alpha=0.93$ & 3.86 & 1.45 \\
\hline IM1 & Pleasure in mastering new ways to help & & 3.71 & 1.68 \\
\hline IM2 & Pleasure in improving quality of environment & & 3.99 & 1.58 \\
\hline IM3 & Pleasure when doing things for the environment & & 3.88 & 1.54 \\
\hline IM4 & Pleasure in contributing to the environment & & 3.85 & 1.55 \\
\hline INTEG & Integrated regulation & $\alpha=0.92$ & 3.69 & 1.43 \\
\hline INTEG1 & An integral part of my life & & 3.68 & 1.60 \\
\hline INTEG2 & Taking care of myself and environment are inseparable & & 3.71 & 1.58 \\
\hline INTEG3 & Has become a fundamental part of who I am & & 3.68 & 1.61 \\
\hline INTEG4 & Part of the way I've chosen to live & & 3.71 & 1.57 \\
\hline IDEN & Identified regulation & $\alpha=0.89$ & 4.23 & 1.40 \\
\hline IDEN1 & Is a sensible thing to do & & 4.43 & 1.61 \\
\hline IDEN2 & A way I have chosen to contribute & & 3.93 & 1.54 \\
\hline IDEN3 & Is a reasonable thing to do & & 4.17 & 1.62 \\
\hline IDEN4 & A good idea to do something about the environment & & 4.42 & 1.65 \\
\hline INTRO & Introjected regulation & $\alpha=0.91$ & 3.80 & 1.50 \\
\hline INTRO1 & I'd regret not doing something & & 3.85 & 1.68 \\
\hline INTRO2 & Would feel guilty if I didn't & & 3.89 & 1.65 \\
\hline INTRO3 & Would feel bad if I didn't do anything & & 3.75 & 1.64 \\
\hline INTRO4 & Would feel ashamed if I didn't & & 3.74 & 1.80 \\
\hline ER & External regulation & $\alpha=0.91$ & 3.11 & 1.43 \\
\hline ER1 & Other people will be upset if I don't & & 3.22 & 1.60 \\
\hline ER2 & For the recognition I get from others & & 3.21 & 1.59 \\
\hline ER3 & Because my friends insist that I do & & 2.97 & 1.62 \\
\hline ER4 & To avoid being criticized & & 3.03 & 1.62 \\
\hline AMO & Amotivation & $\alpha=0.87$ & 3.36 & 1.42 \\
\hline AMO1 & I wonder why; the situation isn't improving & & 3.49 & 1.63 \\
\hline AMO2 & Don't know, have the impression I am wasting time & & 3.21 & 1.62 \\
\hline AMO3 & Don't know, can't see how my efforts are helping & & 3.36 & 1.65 \\
\hline AMO4 & Don't know, can't see what I'm getting out of it & & 3.41 & 1.73 \\
\hline
\end{tabular}

The results of the correlations analyses are shown in Table 3. Only a few differences are observed between the two different calculations of the correlations (Pearson correlation above the diagonal in the table, and correlations between the latent factors in the CFA below the diagonal). Only small differences in values between the two methods are observed, which is in line with the balanced factor loadings observed within each of the constructs in the CFA. The values above as well as below the diagonal in Table 3 reflect a simplex structure.

MTES External Validity and Gender Differences. Pearson correlation between the six MTES dimensions and the different conservation psychological constructs are reported in Table 4; gender differences are shown in Table 5. 
Table 3. Correlations between MTES scales. Pearson correlations above the diagonal, phi-values (correlations between the latent constructs in the confirmatory factor analysis presented in study 1) below the diagonal.

\begin{tabular}{ccccccc}
\hline & IM & INTEG & IDEN & INTRO & ER & AMO \\
\hline IM & --- & $0.75^{*}$ & $0.74^{*}$ & $0.72 *$ & $0.18^{*}$ & $-0.16^{*}$ \\
INTEG & $0.71 *$ & --- & $0.62 *$ & $0.70 *$ & $0.18^{*}$ & $-0.25^{*}$ \\
IDEN & $0.67^{*}$ & $0.59 *$ & --- & $0.70 *$ & $0.12 *$ & $0.09 *$ \\
INTRO & $0.71 *$ & $0.68^{*}$ & $0.66^{*}$ & -- & $0.38^{*}$ & $0.19^{*}$ \\
ER & $0.25^{*}$ & $0.19^{*}$ & $0.14^{*}$ & $0.41 *$ & -- & $0.58^{*}$ \\
AMO & $-0.12 *$ & $-0.19 *$ & 0.05 & 0.03 & $0.45^{*}$ & ---
\end{tabular}

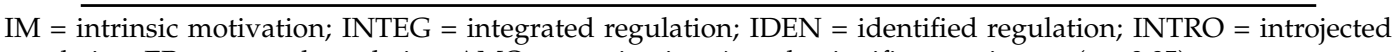
regulation; $\mathrm{ER}=$ external regulation; $\mathrm{AMO}=$ amotivation. ${ }^{*}$ marks significant estimates $(p<0.05)$.

Table 4. Pearson correlations between MTES subscales and other conservation psychological constructs.

\begin{tabular}{ccccccc}
\hline & IM & INTEG & IDEN & INTRO & ER & AMO \\
\hline Preservation values $^{1}$ & $0.45^{*}$ & $0.35^{*}$ & $0.41^{*}$ & $0.42^{*}$ & 0.05 & -0.05 \\
Utlization values $^{1}$ & 0.02 & $0.06^{*}$ & -0.02 & 0.02 & $0.15^{*}$ & $0.15^{*}$ \\
Connectedness to nature $^{1}$ & $0.68^{*}$ & $0.58^{*}$ & $0.59^{*}$ & $0.28^{*}$ & -0.04 & $-0.24^{*}$ \\
Recycling $^{2}$ & $0.28^{*}$ & $0.22^{*}$ & $0.23^{*}$ & $0.24^{*}$ & $0.34^{*}$ & $-0.08^{*}$ \\
Mobility $^{2}$ & $0.19^{*}$ & $0.19^{*}$ & $0.17^{*}$ & 0.07 & $0.18^{*}$ & -0.02 \\
Energy-saving $^{2}$ & $0.21^{*}$ & $0.23^{*}$ & $0.22^{*}$ & $0.12 *$ & $0.19^{*}$ & $-0.24^{*}$ \\
Vicarious behaviors $^{2}$ & $0.32^{*}$ & $0.30^{*}$ & $0.28^{*}$ & 0.07 & 0.02 & $-0.38^{*}$ \\
\hline
\end{tabular}

$\mathrm{IM}=$ intrinsic motivation; INTEG $=$ integrated regulation; IDEN $=$ identified regulation; INTRO = introjected regulation; ER $=$ external regulation; $\mathrm{AMO}=$ amotivation. ${ }^{1}$ based on both samples, $n=1730 .{ }^{2}$ based on the second sample only, $n=951 .{ }^{*}$ marks significant estimates $(p<0.05)$.

Table 5. Gender differences for the MTES.

\begin{tabular}{ccccccc}
\hline & Boys & Girls & \multirow{t}{*}{$\boldsymbol{t}$} & $\boldsymbol{D} f$ & $\boldsymbol{p}$ & $\boldsymbol{d}$ \\
\cline { 2 - 4 } & $\boldsymbol{M} \pm \boldsymbol{S} \boldsymbol{D}$ & $\boldsymbol{M} \pm \boldsymbol{S D}$ & & & & \\
\hline IM & $3.84 \pm 1.45$ & $3.93 \pm 1.45$ & -0.673 & 643 & 0.502 & -0.062 \\
INTEG & $3.70 \pm 1.44$ & $3.67 \pm 1.41$ & 0.188 & 641 & 0.851 & 0.021 \\
IDEN & $4.17 \pm 1.41$ & $4.39 \pm 1.38$ & -1.756 & 640 & 0.080 & -0.158 \\
INTRO & $3.71 \pm 1.50$ & $4.02 \pm 1.48$ & -2.295 & 641 & $0.022 *$ & -0.175 \\
ER & $3.24 \pm 1.44$ & $2.77 \pm 1.32$ & 3.917 & 641 & $0.000 *$ & 0.263 \\
AMO & $3.53 \pm 1.39$ & $2.94 \pm 1.41$ & 4.702 & 640 & $0.000 *$ & 0.351 \\
\hline
\end{tabular}

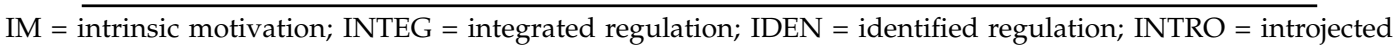
regulation; $\mathrm{ER}=$ external regulation; $\mathrm{AMO}=$ amotivation. ${ }^{*}$ marks significant estimates $(p<0.05)$.

\section{Discussion}

Our goal in this paper was to establish the validity and reliability of a Flemish version of the MTES. Our CFA results confirm the construct validity and as such establish the MTES as an instrument that can be used in its six-factor model not only in its country of origin. Our results also confirm the reliability of the six MTES subscales and, again, show that the scales seem to function nicely in contexts other than the one within which they have been developed. With the construct validity and reliability confirmed, we could move forward with the next steps in our analyses. One goal was to study the interrelations between the six subscales in order to test the hypothesized simplex pattern. Correlations between subscales on the same side of the autonomy vs control continuum correlated highest (e.g., intrinsic motivation and integrated regulation, or externally regulated motivation and amotivation). Connections grew smaller as we correlated constructs that are further away from each other, and eventually even become negative. Though the simplex structure is not complete (some breaks can be observed above and below the diagonal in Table 3), these results do confirm the hypothesized 
influences on the continuum of self-determination. As such, this is again an argument for the validity of the Flemish version of the MTES, as it fits within the theoretically assumed correlation pattern.

In order to test issues of external validity, we correlated the adolescent respondents' MTES data to several well-established environmental psychological constructs. Our hypotheses about the interrelations between the different concepts seem to be confirmed by the analyses. The 2-MEV dimension of preservation correlates positively with intrinsic motivation as well as with the less extrinsically regulated MTES dimensions. No correlations between preservation and external regulation or amotivation were observed. On the other hand, the other 2-MEV dimension of utilization does not correlate with the self-determined forms of motivation, but does correlate with external regulation as well as with amotivation. These inverse, but not opposite correlation patterns match our hypotheses and also further confirm the independent nature of preservation and utilization values as distinctly different but non-opposing constructs [10]. We also observed a significant correlation between the CNS and intrinsic motivation, as well as meaningful correlations between the CNS and integrated and identified regulation. Both of these regulation types tie in with the identification process of individuals, and as such their high correlation with the CNS further supports the validity of the MTES, since the CNS also taps into identification issues. We further observed the CNS to negatively correlate with amotivation which is, again, in line with what was expected here.

The results of the correlation analyses between the MTES and the different behavioral dimensions of the GEB [25] show that patterns of interrelationships between motivation and behavior depend on the behavior in question. Not surprisingly, the more self-determined dimensions in the MTES are those that go together with various behaviors in our adolescent respondents. Furthermore, it is also interesting to observe the differential correlation between amotivation and the different self-reported behaviors (see Table 4). While for mobility there is no such relation, a small negative correlation is observed for recycling behavior and medium correlations for energy-saving and vicarious behaviors. The reasons behind such differential effects are currently unclear, but they are interesting subjects for further research. It is very plausible that they tie into the specific context of adolescents. This context might also explain why differential effect sizes are observed for external regulation. Adolescents are-willingly and/or unwillingly - typically more sensitive to external pressures, such as those of peers, teachers, parents and significant others, than people at any other age. Such external sources of motivation can be very different according to the behavior under scrutiny. Recycling behavior is-in Flanders-more than any other ecological behavior a typically school-moderated behavior on which clear rules and regulations exist in every school. This might explain the high correlation between external regulation and recycling behavior. Similarly, adolescents are not yet fully the owners of their own mobility or energy-saving behaviors. Whichever way we try to explain these correlations, it is clear that the specific context of the respondents plays a crucial role. More research on how these correlations evolve over time as kids become adolescents and then adults can give new and deeper insights into these issues.

We also studied differences between the MTES of girls and boys in our sample. Results show that some gender differences are indeed present. While the observed differences do match with the overall pattern of gender differences in psychosocial environmental constructs, with boys showing greater amotivation and externally regulated motivation than girls, we could not detect the hypothesized differences in intrinsic motivation. However, girls reported a greater introjected regulation than boys. These results may have implications for education and communication initiatives that aim to change the environmental behavior of young people. Boys might be more susceptible to externally regulated motives and associated interventions than girls. Girls, on the other hand, might be more susceptible to feelings of shame when not acting pro-environmentally. However, when judged using Cohen's $d$, the observed gender differences for introjection and external regulation are only small in size (see Table 5), and that for amotivation is intermediate. Moreover, studies suggest that differences between genders could reflect methodological artifacts rather than genuine differences [31]. Caution therefore seems warranted when studying such differences and their implications for real-life scenarios. 
With the validity and reliability of the Flemish version of the MTES established, we can meaningfully interpret the descriptive results for our sample. The most positive answers to items are reported for identified regulation, and then namely for the items that tap into rational motives for acting in favor of the environment. The item with the highest score is "because it is a sensible thing to do". The lowest scoring items are those tapping into externally regulated motivation, second to those tapping into amotivation. In contrast to the descriptive results presented by Pelletier et al. [23], the respondents in our sample do not show great differences between the different subscales. Individual respondents do, however, differ greatly from each other, as indicated by the large standard deviations (SDs) for each item, as well as for each subscale (all above 1.4). The differences between the current results and those of earlier studies (e.g., Pelletier et al. [23]) may be due to several causes. First, there are more than 15 years between the two studies, and thus the results might reflect a societal shift. Second, the results are drawn from samples from different countries, and might reflect differences between Canada and Belgium. Third, the current samples focus only on adolescents, while the sample reported on by Pelletier et al. [23] included participants aged between 17 and 84 years. It is therefore clear that differences between the studies are to be expected, albeit the larger age range in the Canadian study does not seem very plausible as an explanation for the smaller SD. Possible further research could focus on clarifying what lies at the root of the observed differences between the studies. The current results do, however, illustrate the usefulness of the MTES to study differences among (groups of) individuals when studying the drivers of environmental behaviors.

\section{Conclusions and Implications}

The results of our four studies show that the MTES is a valid and reliable instrument which can be used to measure the motivation towards the environment of adolescents, not only within the context in which it was developed, but also in that of Flanders (the Flemish-speaking community of Belgium). While our CFAs show the construct validity of the instrument, with an excellent model fit for all subscale and items, the observed simplex pattern in the correlations shown in the second study underscores the theoretical foundation of the instrument. Furthermore, the diverse relations between the six subscales of the MTES and the different ecological behavior in the third study illustrate the usefulness of the MTES in studying the causation of behavior in different contexts. These results have an implication on the design and evaluation of, e.g., education and outreach initiatives that target ecological behavior. Rather than focusing on specific behaviors, such initiatives could focus on specific types of motivations, so as to build internalized behavior and contribute to sustained behavior change. The MTES could, in such a context, be used to survey participant motivational profiles, which would allow for targeted interventions. Also, if designers of interventions define self-determined motivation as one of their goals, then the MTES presents an excellent instrument to study the impact of the intervention. While our current study has expanded the support for the MTES's validity and reliability, (replication) studies in other cultural contexts and with other age groups are the next steps toward establishing the MTES as a widely recognized and validated instrument that builds on the widely endorsed and applied self-determination theory.

Acknowledgments: We are grateful for all the students that provided data, and for the teachers that facilitated data collection.

Author Contributions: Jelle Boeve-de Pauw and Peter Van Petegem designed the study and wrote the paper. Jelle Boeve-de Pauw collected and analyzed data.

Conflicts of Interest: The authors declare no conflict of interest.

\section{References}

1. Cardinale, B.J.; Duffy, J.E.; Gonzalez, A.; Hooper, D.A.; Perrings, C.; Venail, P.; Narwani, A.; Mace, G.M.; Tilman, D.; Wardle, D.A.; et al. Biodiversity loss and its impact on humanity. Nature 2012, 486, 59-67. [CrossRef] [PubMed] 
2. Lebreton, L.C.-M.; Greer, S.D.; Borreo, J.C. Numerical modeling of floating debris in the world's oceans. Mar. Pollut. Bull. 2012, 64, 653-661. [CrossRef] [PubMed]

3. Slezakova, K.; Castro, D.; Delerue-Matos, C.; Alvim-Ferraz, M.; Morais, S.; Pereira, M. Impact of vehicular traffic emissions on particulate-bound PAHs: Levels and associated health risks. Atmos. Res. 2013, 127, 141-147. [CrossRef]

4. Schultz, P.W. Conservation means behavior. Conserv. Biol. 2011, 25, 1080-1083. [CrossRef] [PubMed]

5. Diaz, S.; Fargione, J.; Chapin, F.S., III; Tilman, D. Biodiversity loss threatens human well-being. PLoS Biol. 2006, 4, e277. [CrossRef] [PubMed]

6. Balmford, A.; Cowling, R. Fusion or failure? The future of conservation biology. Conserv. Biol. 2006, 20, 692-695. [CrossRef] [PubMed]

7. Schultz, P.W.; Gouveia, V.V.; Cameron, L.D.; Tankha, G.; Schmuck, P.; Franek, M. Values and their relationship to environmental concern and conservation Behavior. J. Cross-Cult. Psychol. 2005, 36, 457. [CrossRef]

8. Roczen, N.; Kaiser, F.; Bogner, F.; Wilson, M. A competence model for environmental education. Environ. Behav. 2004, 46, 972-992. [CrossRef]

9. Dunlap, R.E.; Van Liere, K.D.; Mertig, A.G.; Jones, R.E. Measuring endorsement of the New Ecological Paradigm: A revised NEP scale. J. Soc. Issues 2000, 56, 425-442. [CrossRef]

10. Bogner, F.X.; Wiseman, M. Adolescents' attitudes toward nature and environment: Quantifying the 2-MEV model. Environmentalist 2006, 26, 247-254. [CrossRef]

11. Schultz, P.W.; Tabanico, J. Self, identity, and the natural environment: Exploring implicit connections with nature. J. Appl. Soc. Psychol. 2007, 37, 1219-1247. [CrossRef]

12. Mayer, F.S.; Frantz, C.M. The connectedness to nature scale: A measure of individuals' feeling in community with nature. J. Environ. Psychol. 2004, 24, 503-5015. [CrossRef]

13. Ajzen, I. From intentions to actions: A theory of planned behavior. In From Cognition to Behavior; Kuhl, J., Beckmann, J., Eds.; Springer: Berlin/Heidelberg, Germany, 1985.

14. Stern, P.C.; Dietz, T.; Abel, T.; Guagnano, G.A.; Kalof, L. A value-belief-norm theory of support for social movements: The case of environmentalism. Res. Hum. Ecol. 1999, 6, 81-97.

15. Boeve-de Pauw, J.; Van Petegem, P. The effect of eco-schools on children's values and behavior. J. Biol. Educ. 2013, 47, 96-103. [CrossRef]

16. Lieflander, A.; Frohlich, F.; Bogner, F.X.; Schultz, W. Promoting connectedness with nature through environmental education. Environ. Educ. Res. 2013, 19, 370-384. [CrossRef]

17. Johnson, B.; Manoli, C.C. Using Bogner and Wiseman's Model of Ecological Values to measure the impact of an earth education programme on children's environmental perceptions. Environ. Educ. Res. 2008, 14, 115-127. [CrossRef]

18. Deci, E.L.; Ryan, R.M. Intrinsic Motivation and Self-Determination in Human Behavior; Plenum: New York, NY, USA, 1985.

19. Deci, E.L. The effects of contingent and noncontingent rewards and controls on intrinsic motivation. Organ. Behav. Hum. Decis. Proc. 1972, 8, 217-229. [CrossRef]

20. Osbaldistan, R.; Sheldon, K.M. Promoting internalized motivation for environmentally responsible behavior: A prospective study of environmental goals. J. Environ. Psychol. 2003, 23, 349-357. [CrossRef]

21. Deci, E.L.; Ryan, R.M. The "what" and "why" of goal pursuits: Human needs and the self-determination of behavior. Psychol. Inq. 2000, 26, 227-346. [CrossRef]

22. Villacorta, M.; Koenster, R.; Lekes, N. Further validation of the motivation towards the environment scale. Environ. Behav. 2003, 35, 486-505. [CrossRef]

23. Pelletier, L.G.; Tuson, K.M.; Green-Demers, I.; Noels, K.; Beaton, A.M. Why are you doing things for the environment? The Motivations toward the Environment Scale (MTES). J. Appl. Soc. Psychol. 1998, 28, 437-468. [CrossRef]

24. Legault, L.; Pelletier, L. Impact of an environmental education program on students' and parents' attitudes, motivation, and behaviours. Can. J. Behav. Sci. 2000, 32, 243-250. [CrossRef]

25. Kaiser, F.; Wilson, M. Assessing people's general ecological behavior: A cross-cultural measure. J. Appl. Soc. Psychol. 2000, 30, 952-978. [CrossRef]

26. De Groot, J.I.M.; Steg, L. Relationships between value orientations, self-determined motivational types and pro-environmental intententions. J. Environ. Psychol. 2010, 30, 368-378. [CrossRef] 
27. Schwartz, S.H. Are there universal aspects in the structure and contents of human values? J. Soc. Issues 1994, 50, 19-45. [CrossRef]

28. Verplanken, B.; Holland, R. Motivated decision making: Effects of activation and self-centrality of values on choices and behavior. J. Pers. Soc. Psychol. 2002, 82, 434-447. [CrossRef] [PubMed]

29. De Groot, J.I.M.; Steg, L. Value orientations to explain environmental attitudes and beliefs: How to measure egoistic, altruistic and biospheric value orientations. Environ. Behav. 2008, 40, 330-354. [CrossRef]

30. Milfont, T.L.; Duckitt, J.; Cameron, L.D. A cross-cultural study of environmental motives concerns and their implication for environmental behavior. Environ. Behav. 2006, 38, 745-767. [CrossRef]

31. Boeve-de Pauw, J.; Jacobs, K.; Van Petegem, P. Gender differences in the environmental values: An issue of measurement? Environ. Behav. 2014, 46, 373-397. [CrossRef]

32. Frantz, C.M.; Mayer, F.S. The importance of connection to nature in assessing environmental education programs. Stud. Educ. Eval. 2014, 41, 85-89. [CrossRef]

33. Kaiser, F. A moral extension of the theory of planned behavior: Norms and anticipated feelings of regret in conservationism. Pers. Individ. Differ. 2006, 41, 71-81. [CrossRef]

34. Zelezny, L.C.; Chua, P.-P.; Aldrich, C. Elaborating on gender differences in environmentalism. J. Soc. Issues 2000, 56, 443-457. [CrossRef]

35. Schahn, J.; Holzer, E. Studies of individual environmental concern: The role of gender, knowledge and background variables. Environ. Behav. 1990, 22, 767-786. [CrossRef]

36. Goldman, D.; Yavetz, B.; Pe'er, S. Environmental literacy in teacher training in Israel: Environmental behavior in new students. J. Environ. Educ. 2006, 38, 3-22. [CrossRef]

37. Eagly, A. Gender Differences in Social Behavior: A Social Role Interpretation; Lawrence Erlbaum: Hillsdale, NJ, USA, 1987.

38. Vallerand, R.J.; Pelletier, L.G.; Blais, M.R.; Briere, N.M.; Senecal, C.; Vallieres, E.F. The academic motivation scale: A measure of intrinsic, extrinsic and amovition in education. Educ. Psychol. Meas. 1992, 52, 1003-1017. [CrossRef]

39. Guay, F.; Chanal, J.; Ratelle, C.; Marsh, H.W.; Larose, S.; Boivin, M. Intrinsic, identified, and controlled types of motivation for school subjects in young elementary school children. Br. J. Educ. Psychol. 2010, 80, 711-735. [CrossRef] [PubMed]

40. Perenger, T.V. What's wrong with Bonferroni adjustments. Br. Med. J. 1998, 136, 1236-1238. [CrossRef]

41. O'Keefe, D.; Colloquy, J. Should familywise alpha be adjusted? Against familywise alpha adjustment. Hum. Commun. Res. 2003, 29, 431-447. [CrossRef]

42. Muthén, L.K.; Muthén, B.O. Mplus User Guide; Muthén \& Muthén: Los Angeles, CA, USA, 2010.

43. Tabachnick, B.G.; Fidel, L.S. Using Multivariate Statistics; Pearson Education: Boston, MA, USA, 2007.

44. Muthén, L.K.; Muthén, B.O. Mplus User Guide; Muthén \& Muthén: Los Angeles, CA, USA, 2007. 